Original Article

\title{
A study on the sleep quality, pain, and instrumental activities of daily living of outpatients with chronic stroke
}

\author{
JuHyung PARK, PhD, OT ${ }^{1)}$ \\ 1) Department of Occupational Therapy, Health Science College, Cheongju University: \\ 298 Daesung-ro, Cheongwon-gu, Cheongju 363-764, Republic of Korea
}

\begin{abstract}
Purpose] The purpose of this study is to examine the sleep quality, pain, and instrumental activities of daily living (IADL) of outpatients with chronic stroke, and to examine their correlation. [Participants and Methods] This study was conducted on 42 outpatients with chronic stroke, and data on their sleep quality, pain, and instrumental activities of daily living were collected and analyzed using the survey measurement tools. [Results] The analysis shows significant correlations among the sleep quality, pain, and instrumental activities of daily living of the outpatients with chronic stroke. [Conclusion] The findings of this study confirmed that the sleep quality and pain of outpatients with chronic stroke was related with their capacities of instrumental activities of daily living. Key words: IADL, Quality of sleep, Stroke
\end{abstract}

(This article was submitted Aug. 10, 2018, and was accepted Nov. 7, 2018)

\section{INTRODUCTION}

Sleeping is a mechanism to recover the physical functions, maintain strength and recharge human physical and emotional energies, as the most important resting method in an unconscious state from which one can be awoken by an adequate sensory stimulus ${ }^{1)}$. In other words, sleeping is essential for well-being, daily activities and maintenance of homeostasis ${ }^{2)}$. On the other hand, sleep quality deteriorates in most patients after the onset of stroke, ultimately manifesting in a number of sleeping problems, including more frequent drowsiness during the day and a general fatigue that affects their participation in rehabilitation programs and the performance of daily activities ${ }^{3-5)}$. In addition, it has been reported that about $30-50 \%$ of stroke patients complain of a number of pains such as shoulder pain, headache, topic pain, or central pain after the onset ${ }^{6,7)}$. If these pains are prolonged, other pain-related symptoms such as sleeping disorder, insecurity, depression, or fear may be accompanied. Furthermore, these could cause disabilities in daily activities, decline in social activities, etc ${ }^{8,9)}$. Generally, previous studies have mentioned a number of factors that affect daily activities of stroke patients such as the degree of brain damage, motor skill damage, time for rehabilitative therapy, level of cognitive and sensory disabilities, and depression levels, etc. ${ }^{10)}$ but only a few studies focus on the sleep quality, pain, and basic activities of daily living (BADL). Significantly, few studies have reported correlations among the capacities of instrumental activity of daily living (IADL), pain and sleep quality, the importance of which will relatively increase due to the characteristics of patients with chronic stroke, who spend most of their time in their local communities, including their household in the chronic phase of their disease after the initial hospitalization phase. In the preceding studies that have examined the correlation between sleep quality ${ }^{11}$, sleep satisfaction, feeling of fatigue, and quality of life in 37 stroke patients, it was mentioned that sleep satisfaction relates to feeling of fatigue and quality of life and thus, it is necessary to consider the factors related to sleep for the effective rehabilitation of stroke patients. In addition, pain is a subjective feeling of the individual, which can be regarded as an emotional factor that hinders the rehabilitation of stroke patients. In other words, sleep quality and pain would be not only precedence elements for 
Table 1. General characteristic of the participants

\begin{tabular}{llll}
\hline & & Mean \pm SD & Frequency $(\%)$ \\
\hline Age (years) & & $65.76 \pm 2.55$ & \\
Onset (months) & & $25.17 \pm 10.05$ & \\
\multirow{2}{*}{ Gender } & Male & & $20(47.61 \%)$ \\
& Female & & $22(52.38 \%)$ \\
Paretic side (Right/Left) & Right & & $19(45.23 \%)$ \\
& Left & $23(54.76 \%)$ \\
\hline
\end{tabular}

All variables are mean \pm standard deviation $(\mathrm{SD})$.

overall effective treatments and physical therapies for rehabilitation of stroke patients, but also factors to predict the success of rehabilitation. This study examines the correlation among sleep quality, pain, and capacities of IADL of outpatients with chronic stroke.

\section{PARTICIPANTS AND METHODS}

This study was conducted on 42 patients receiving outpatient care in three hospitals in South Korea after being diagnosed with hemiplegia by stroke. The sample size calculation was based on effect size $0.5,80 \%$ power, level of significance 0.05 , using G-power version 3.01. The required sample size was 29. The selection criteria of the participants were a score of 24 or above on the Korean version of Mini-Mental State Examination (MMSE-K), the absence of illnesses other than stroke, and the absence of speech disorder. All of the study participants were fully informed of the purpose of this study before submitting their voluntary consent to participate. This study complied with the ethical standards of the Declaration of Helsinki. Table 1 shows the general characteristics of the participants.

The Pittsburgh Sleep Quality Index (PSQI) was used on the participants. As a self-reporting tool, the PSQI assesses seven components - namely, sleep latency, sleep duration, use of sleeping medication, habitual sleep efficiency, subject sleep quality, sleep disturbance, and daytime dysfunction - using 19 questions. Each field is measured on a scale of 0 to 3, and the total score is in the range of $0-21$ with a total score of 5 or higher indicating bad sleep quality. The reliability was Cronbach's $\alpha=0.83$, and the test-retest reliability was $0.85^{12,13}$. The Korean Instrumental Activities of Daily Living (K-IADL) was used to assess IADL. The K-IADL consists of seven components: grooming, housework, preparing meals, laundry, short-distance outings, access to transportation, shopping, managing money, using a telephone, and taking medicine. With a scale of 0 to 3 , the total score ranges from 0 to 33, but 'not applicable' was added to each component in consideration of gender norms. Therefore when grading, the total scores of the components were summed up, excluding the ones checked as not applicable, and then divided by the number of the components to calculate the average. Here, a lower score indicated better capacity. In terms of the reliability of this tool, the test-retest reliability was as high as $r=0.94$ and Cronbach's $\alpha$ of $0.96^{14)}$. To assess the pain level, the Numeric Rating Scale (NRS) was used to express subjective and different pains comprehensibly in the form of a number in a short period of time. With a scale of 0 to 10 , the NRS indicates pain level using a numeric figure: 0 means no pain, and 10 means the most severe pain. A higher score on the NRS indicates more severe pain. The NRS has been reported as having high feasibility and sensitivity for pain level assessment ${ }^{15)}$. SPSS Version 18.0 was used to carry out the statistical analysis for this study. The overall significance level was set to $p<0.05$. Descriptive statistics and frequency analysis were applied to the general characteristics, and Pearson's correlation coefficient was applied to examine the correlations among sleep quality, pain and IADL.

\section{RESULTS}

The analysis showed the total score of the participants' capacities of IADL as $23.39 \pm 6.37$ on average. The average total score of sleep quality was $7.45 \pm 3.85$, and the average total pain score was $3.67 \pm 2.88$. Table 2 shows the correlations among the participants' capacities of daily activities, pain, and sleep quality (Table 2). If we look into the correlation between the instrumental activities of daily living and the sleep quality of the participants, there was a statistically significant correlation $(p<0.05)$ between grooming, housework, preparing meals, laundry, shopping, managing money, using a telephone and the total score, and there was no significant correlation between items such as short-distance outings, access to transportation and taking medicine. As an analysis of the instrumental activities of daily living and the degree of pain of the participants, a significant correlation was shown in all items with the exception of items such as preparing meals and taking medicine $(\mathrm{p}<0.05)$. 
Table 2. The correlation between K-IADL, QOS, pain degree

\begin{tabular}{lll}
\hline K-IADL item & QOS & NRS \\
\hline Grooming & $0.410^{*}$ & $0.391^{*}$ \\
Housework & $0.338^{*}$ & $0.269^{*}$ \\
Preparing meals & $0.281^{*}$ & 0.195 \\
Laundry & $0.307^{*}$ & $0.291^{*}$ \\
Short-distance out & 0.112 & $0.342^{*}$ \\
Access to transportation & 0.284 & $0.349^{*}$ \\
Shopping & $0.397^{*}$ & $0.328^{*}$ \\
Managing money & $0.307^{*}$ & $0.276^{*}$ \\
Using telephone & $0.352^{*}$ & $0.299^{*}$ \\
Taking medicine & 0.156 & 0.149 \\
Total & $0.394^{*}$ & $0.374^{*}$ \\
NRS & $0.743^{*}$ & \\
\hline
\end{tabular}

$* \mathrm{p}<0.05$. K-IADL: Korean Instrumental Activities of Daily Living; QOS: Quality of Sleep; NRS: Numeric Rating Scale.

\section{DISCUSSION}

This study examined the correlations among the variables by measuring the sleep quality, pain level, and IADL of outpatients with chronic stroke. The findings confirmed significant correlations between the sleep quality and pain level of participants with most components of the K-IADL, showing similar results to previous studies that reported high dependence in daily living was correlated with a long sleeping time during day and less sleeping time at night, and that frequent waking during sleep had a negative impact on the capacity for daily activities ${ }^{16}$. A study reported the possibly negative impact of bad sleep quality on the psychological, physiological, physical, and cognitive functions and functional recovery, which is in line with this study's findings on the significant correlations among the capacities of IADL and sleep quality of outpatients with chronic stroke ${ }^{11)}$. And, in the result of this study, it was shown that there was a significant correlation $(p<0.05)$ with the quality of sleep in items such as grooming, housework, preparing meals, laundry, shopping, managing money, using the telephone, etc., which relatively require the physical ability of the participants, whereas there was no significant correlation $(p<0.05)$ with the quality of sleep in items such as short-distance outings, access to transportation, and taking medicine, where the nature of the item means that the use of assistive devices is the major part for activity or the use of the non-impaired side is relatively not needed. This is consistent with the results that have been reported in the preceding studies that investigated the correlation between basic daily activities and sleep quality of patients with stroke where no correlation was found in the items that could be easily compensated by the non-impaired side, while there was significant correlation in the activities requiring relatively more functions of the impaired side ${ }^{17)}$. This study showed a significant correlation between pain and capacities of IADL, which is consistent with the research findings that mentioned a high pain level resulting in limited and passive ability to perform daily activities ${ }^{18)}$. The findings of this study describe significant correlations among the sleep quality, pain level, and IADL of chronic stroke patients, suggesting the importance of individual intervention and observation on pain levels and sleep quality affecting IADL in order to encourage and improve the participation of outpatients with chronic stroke in their local communities. A limitation of this study is that it is difficult to generalize the results of the research due to the limited number of participants, and the limited regions and institutions involved. In addition, because it is a cross-sectional study, it cannot observe the changes varying on variables over time. In addition, motor paralysis, sensory deficit, region of stroke, area of pain, and types of pain were not investigated in this study. Future studies should address these limitations.

\section{Conflict of interest}

None.

\section{REFERENCES}

1) Foreman MD, Wykle M, The NICHE Faculty: Nursing standard-of-practice protocol: sleep disturbances in elderly patients. Geriatr Nurs, 1995 , 16: $238-243$. [Medline] [CrossRef]

2) Moldofsky H, Scarisbrick P, England R, et al.: Musculosketal symptoms and non-REM sleep disturbance in patients with "fibrositis syndrome" and healthy subjects. Psychosom Med, 1975, 37: 341-351. [Medline] [CrossRef]

3) Palomäki H, Berg A, Meririnne E, et al.: Complaints of poststroke insomnia and its treatment with mianserin. Cerebrovasc Dis, 2003, 15: 56-62. [Medline] [CrossRef] 
4) Sterr A, Herron K, Dijk DJ, et al.: Time to wake-up: sleep problems and daytime sleepiness in long-term stroke survivors. Brain Inj, 2008, 22: 575-579. [Medline] [CrossRef]

5) Gottselig JM, Bassetti CL, Achermann P: Power and coherence of sleep spindle frequency activity following hemispheric stroke. Brain, 2002, 125: 373-383. [Medline] [CrossRef]

6) Lee EC, Huun SH, Min KD, et al.: A case study of Central Post-Stroke Pain (CPSP) treated with Korean medical treatment. J Intern Korean Med, 2013, 34: 194-200.

7) Klit H, Finnerup NB, Jensen TS: Central post-stroke pain: clinical characteristics, pathophysiology, and management. Lancet Neurol, 2009, 8: 857-868. [Medline] [CrossRef]

8) Härter M, Reuter K, Weisser B, et al.: A descriptive study of psychiatric disorders and psychosocial burden in rehabilitation patients with musculoskeletal diseases. Arch Phys Med Rehabil, 2002, 83: 461-468. [Medline] [CrossRef]

9) Jönsson AC, Lindgren I, Hallström B, et al.: Prevalence and intensity of pain after stroke: a population based study focusing on patients' perspectives. J Neurol Neurosurg Psychiatry, 2006, 77: 590-595. [Medline] [CrossRef]

10) Aström M, Adolfsson R, Asplund K: Major depression in stroke patients. A 3-year longitudinal study. Stroke, 1993, 24: 976-982. [Medline] [CrossRef]

11) Jang YS, Kim HD, Chung HA: Correlations among the sleep, fatigue and quality of life in patients with stroke. J Korea Academia-Industrial Coop Soc, 2013, 14: 6302-6308. [CrossRef]

12) Tang WK, Grace Lau C, Mok V, et al.: Insomnia and health-related quality of life in stroke. Top Stroke Rehabil, 2015, 22: 201-207. [Medline] [CrossRef]

13) Zhang S, Chang C, Zhang J, et al.: Correlation analysis of sleep quality and youth ischemic stroke. Behav Neurol, 2014, 2014: 246841. [Medline] [CrossRef]

14) Kang SJ, Choi SH, Lee BH, et al.: The realiability and validity of the korean instrumental activities of daily living (K-IADL). J Korean Neurol Assoc, 2002, 20: $8-14$.

15) Von Korff M, Jensen MP, Karoly P: Assessing global pain severity by self-report in clinical and health services research. Spine, 2000, 25: 3140-3151. [Medline] [CrossRef]

16) Bakken LN, Kim HS, Finset A, et al.: Stroke patients' functions in personal activities of daily living in relation to sleep and socio-demographic and clinical variables in the acute phase after first-time stroke and at six months of follow-up. J Clin Nurs, 2012, 21: 1886-1895. [Medline] [CrossRef]

17) Ju SH, Kim H: Impact of sleep quality and pain degree on the activities of daily living in patients with stroke. J Korean Soc Occup Ther, 2017, 25: 27-39. [CrossRef]

18) Cha YJ, Kim K: Reliability and validity of the Korean version of the fear of daily activities questionnaire for patients with low back pain. J Digit Contents Soc, 2011, 11: 224-231. 